\title{
Presence as a personal project in palliative care: transcending personality
}

\author{
Emmerentia du Plessis* \\ INSINQ Research Focus Area, School of Nursing Science, North-West University, Potchefstroom Campus, South Africa
}

\begin{abstract}
Presence creates a space of healing and closure for patients who receive palliative care. Presence may be linked to personality, which raises the question how presence can be fostered in nurses who do not have a natural gift to "be with" patients. The idea of personal projects may offer an answer, as it is argued that such personal projects transcend personality. The personal projects of nurses in palliative care should thus be explored and aligned with presence in order for the creation of a healing space. Ways to foster presence in this manner are discussed.
\end{abstract}

The nature of palliative care calls for an in-depth look at the value presence holds for both patients and nurses. Presence creates a space of hope, calmness and stillness, it allows time for reflection, it brings acceptance and it allows space for palliative patients to express deep emotions and find inner healing. Madeleine Clemence Vaillot introduced the concept presence as 'being there with the whole self for the patient in times of need' [1]. Presence, the art of being in the moment, creates a space of healing for both nurses and patients. Patients experience being honoured and accepted and experience palliative care as positive; restoring hope and optimism. For nurses, creating a space of healing through presence, bring fulfilment and a heightened sense of purpose and meaning.

To be present, nurses should deliberately choose and be willing to become vulnerable, share in the distressing experience of patients, engage in the intentional process of presence, spend time with patients, internalise each other's struggles, and share personal energy to diminish each other's stress [2]. Foundational values enable nurse to be present, including respect for individual differences, unconditional positive regard, commitment to help in a respectful and non-judgemental manner regardless of the circumstances, and placing emphasis on patient enablement, empowerment and self-care [2]. Presence requires serenity and silence, the ability to be quiet in inner dialogue, to hear clearly and to allow others to share [3].

It is clear that presence requires much from nurses. For some nurses, presence may be an innate gift and natural characteristic [1]. In our research on presence, and when talking informally with nurses or when experiencing care provided by nurses, one can almost immediately distinguish between nurses who are truly in the moment with their patients-focusing on the needs of their patients-and those who are less present. If presence is, therefore, an innate characteristic, the question arises whether nurses with specific personalities may be more prone to be present in the moment, along with the concern whether nurses who are not naturally inclined to presence can indeed be present for patients.

Personality may be linked to presence, as personality can be viewed as consistent and distinctive patterns of behaviour and "the most important way in which individuals differ in their enduring emotional, interpersonal, experiential, attitudinal and motivations styles" [4]. One of the most well-known personality typologies is the Myers-Briggs personality system, based on the work of Carl Jung. In this system, 16 personalities are identified according to specific combinations of the following modalities: introversion/extraversion (where the attention of persons is focused); feeling/thinking (how decisions are made); intuition/sensing (how information is taken in) and judging/perceiving (how persons deal with the world). If applied to the argument regarding presence, it seems that it may be more natural for nurses with an intuitive and feeling personality, also referred to as a diplomatic personality, or with a sensing and perceiving personality, referred to as an exploring personality, to focus on 'being there for' and 'being present in the moment'. Another view on personality is the 5 -factor model of personality, namely that personality is a hierarchical organisation of personality traits in the dimensions of openness to experience $(\mathrm{O})$; conscientiousness $(\mathrm{C})$; extraversion $(\mathrm{E})$; agreeableness (A); and neuroticism (N) [4]. The following example can be provided: a high $\mathrm{O}$ score is associated with being imaginative, perceptive and creative. $\mathrm{C}$ is described as being prudent and having a will to achieve. A high score in $\mathrm{E}$ means that persons have high energy, a positive affectivity and warmth. A is associated with altruism, nurturance, caring and emotional support while a low score in $\mathrm{N}$ indicates calm, relaxed, even-tempered persons [4].

If it is a valid argument that presence is associated with personality, and if we view presence as beneficial and something that should be encouraged in palliative care, the question arises how presence can be fostered in nurses who may not be naturally inclined to be present.

Correspondence to: Emmerentia du Plessis, $\mathrm{PhD}$, Registered nurse, Nurse educator, Associate Professor, INSINQ Research Focus Area, School of Nursing Science, North-West University, Potchefstroom Campus, South Africa, Tel: 27182991876; E-mail: Emmerentia.duPlessis@nwu.ac.za

Key words: palliative care, personality, personal project, presence

Received: November 18, 2016; Accepted: December 15, 2016; Published: December 19, 2016 
The 'personality projects' view may offer an answer to this question. Dr Brian Little introduced the concept 'personality projects' into personality research [5] and argues that while personality is generic and typical of individuals, personal projects can transcend personality. Personal projects are extended sets of actions [6] and are representative of the salient life goals of individuals [7]. Personal projects can be ongoing (for example, following a specific career); single events (for example, advocating for a patient); or relational (for example, building trust relationships with patients) and are individually defined and valued by persons [8].

If applied to palliative care, this can mean that nurses who are naturally closed to new experiences may choose to be there with oncology patients and explore new possibilities of treatment with their patients - if the personal project of these nurses to ensure that the needs of their patients are met. Another example is that a personal project of valuing human rights may motivate nurses to move from their natural tendency of introversion to 'being there' and boldly advocate for humane treatment of dying AIDS patients in a large meeting of multiprofessional team members. In other words, even if a nurse in palliative care is not naturally inclined to presence, a personal project of having passion for palliative care and nursing can move nurses to be present with their patients. In promoting presence in palliative nursing, it seems, therefore, important to find out from nurses what their personal projects are, and to promote and support those personal projects that align with presence.

When examining ways to promote presence as a personal project, role modelling should be considered. Presence can be fostered through practices, such as reflection on experiences during practice; by emphasising the traditional nursing arts: holding hands, being with patients, sitting and talking to them, and giving backrubs [1]; and through techniques, such as journaling, meditation exercises, and mindfulness practice (e.g., walking, prayer, breathing and reflection) [9]. Ceremonies, artwork and symbols of healing may also provide opportunities to foster presence [10]. Quiet time and centering with the here-and-now moment-as preparation for being present with others-are also ways to become present [1]. Nursing education and informal ongoing training should, therefore, be tailored in this regard - an awareness of personal projects of nurses in palliative care should be promoted.

In this way, presence can blend into a nurse-patient relationship, and nurses can apply their unique personality and wisdom to create a healing space according to the readiness and needs of patients and situations. Nurses can then make use of assessments, planning, intervention and evaluations as opportunities to be present through vigilance, going beyond what is expected of them, being creative and acting on behalf of patients [2]. Presence then becomes evident through availability; caring attention; providing comfort; competent performance of nursing procedures; patient education; and coordination of care with other healthcare providers [11]. 'Such actions create a therapeutic healing experience, thereby improving quality of life and engendering a psychospiritual peace' [11]. Being present in a unique way-motivated by a personal project-nurses become fully and holistically present [12] and open to the moment [13]. Such presence manifests in unique ways in therapeutic and affectionate touch; centering; attentive and therapeutic silence; truly listening; eye contact; smiling; a sense of humour, a positive and congruent body posture; sharing stories; and attending to the personal needs of patients [14]. This presence may also be evident through a calm and quiet tone of voice, and through answering questions and providing explanations [12] and may also simply entail that nurses are present in an engaged, gentle, authentic manner with a stillness of spirit, and that nurses become the intervention [15]. These interactions communicate respect and acknowledgement, and foster connectedness and self-discovery [12], and may bring much longed for closure and hope for patients in palliative care.

\section{Authorship}

Prof. Emmerentia du Plessis conceptualised and wrote the manuscript.

\section{Acknowledgement}

I would like to thank Ms Mari Grobler for the language editing of the manuscript.

\section{References}

1. Bright AL (2012) Presence in nursing practice: a critical hermeneutic analysis. San Francisco: University of San Francisco (Doctoral dissertation-PhD).

2. Finfgeld-Connett D (2008) Qualitative comparison and synthesis of nursing presence and caring. Int J Nurs Terminol Classif 19: 111-119. [Crossref]

3. Stanley KJ (2002) The healing power of presence: respite from the fear of abandonment. Oncol Nurs Forum 29: 935-940. [Crossref]

4. McCrae RR, John OP (1992) An introduction to the five-factor model and its applications. J Pers 60: 175-215. [Crossref]

5. Little BR (1983) Personal projects: A rationale and method for investigation. Environ Behav 15: 273-309.

6. Little BR, Lecci L, Watkinson B (1992) Personality and personal projects: linking big five and PAC units of analysis. J Pers 60: 501-525. [Crossref]

7. Presseau J, Sniehotta FF, Francis JJ, Little BR (2008) Personal project analysis: opportunities and implications for multiple goal assessment, theoretical integration, and behaviour change. European Health Psychologist 10: 32-36.

8. Egan M, Scott-Lowery L, De Serres Larose C, Gallant L, Jaillet C (2016) The use of personal projects analysis to enhance occupational therapy goal identification. The Open Journal of Occupational Therapy 4.

9. McCollum EE, Gehart DR (2010) Using mindfulness meditation to teach beginning therapists therapeutic presence: a qualitative study. J Marital Fam Ther 36: 347-360.

10. Coffman S (2007) Healing presence ceremony in nursing education. Int J Hum Caring 11: $52-56$.

11. Kostovich CT (2012) Development and psychometric assessment of the Presence of Nursing Scale. Nurs Sci $Q 25: 167-175$. [Crossref]

12. Zikorus $P$ (2007) The importance of a nurse's presence: a personal story of holistic caring. Holist Nurs Pract 21: 208-210. [Crossref]

13. Nelms TP (1996) Living a caring presence in nursing: a Heideggerian hermeneutical analysis. $J A d v$ Nurs 24: 368-374. [Crossref]

14. Hooper VD (2013) The caring presence of nursing: a qualitative focus. $J$ Perianesth Nurs 28: 255-256. [Crossref]

15. Rowe J, Kellam C (2013) The provider's role in promoting hope for patients in clinical encounters. Home Health Care Manag Pract 25: 135-140.

Copyright: (C2016 Plessis E. This is an open-access article distributed under the terms of the Creative Commons Attribution License, which permits unrestricted use, distribution, and reproduction in any medium, provided the original author and source are credited. 